\title{
Effects of Regional Anesthesia on Phantom Limb Pain Are Mirrored in Changes in Cortical Reorganization
}

\author{
Niels Birbaumer, ${ }^{1,4}$ Werner Lutzenberger, ${ }^{1}$ Pedro Montoya, ${ }^{1}$ Wolfgang Larbig, ${ }^{1}$ Klaus Unertl, ${ }^{2}$ \\ Stephanie Töpfner, ${ }^{2}$ Wolfgang Grodd, ${ }^{3}$ Edward Taub, ${ }^{5}$ and Herta Flor ${ }^{6}$ \\ 1/nstitute of Medical Psychology and Behavioral Neurobiology, and Departments of ${ }^{2}$ Anesthesiology and ${ }^{3}$ Neuroradiology, \\ University of Tübingen, D-72074 Tübingen, Germany, ${ }^{4}$ Department of Psychology, University of Padova, I-35131 Padova, \\ Italy, ${ }^{5}$ Department of Psychology, University of Alabama at Birmingham, Birmingham, Alabama 35294-1170, and \\ 6Department of Psychology, Humboldt-University, D-10117 Berlin, Germany
}

The causes underlying phantom limb pain are still unknown. Recent studies on the consequences of nervous system damage in animals and humans reported substantial reorganization of primary somatosensory cortex subsequent to amputation, and one study showed that cortical reorganization is positively correlated with phantom limb pain. This paper examined the hypothesis of a functional relationship between cortical reorganization and phantom limb pain. Neuroelectric source imaging was used to determine changes in cortical reorganization in somatosensory cortex after anesthesia of an amputation stump produced by brachial plexus blockade in six phantom limb pain patients and four pain-free amputees. Three of six phantom limb subjects experienced a virtual elimination of current phantom pain attributable to anesthesia (mean change: 3.8 on an 11-point scale; $Z=-1.83 ; p<0.05$ ) that was mirrored by a very rapid elimination of cortical reorganization in somatosensory cortex (change $=19.8 \mathrm{~mm} ; t_{(2)}=5.60 ; p<0.05$ ). Cortical reorganization remained unchanged (mean change $=1.6 \mathrm{~mm}$ ) in three phantom limb pain amputees whose pain was not reduced by brachial plexus blockade and in the phantom painfree amputation controls. These findings suggest that cortical reorganization and phantom limb pain might have a causal relationship. Methods designed to alter cortical reorganization should be examined for their efficacy in the treatment of phantom limb pain.

Key words: phantom limb pain; cortical reorganization; brachial plexus anesthesia; neuroelectric source imaging; human; pain treatment; plasticity; EEG
Phantom limb pain, i.e., pain that is experienced in a limb that is no longer present, affects $\sim 50-80$ percent of amputees (Sherman and Sherman, 1983; Jensen et al., 1985). Although both peripheral (Sherman et al., 1989; Arena et al., 1990; Katz, 1992a) and central (Katz and Melzack, 1990; Melzack, 1990, 1995) mechanisms have been implicated in the development of phantom limb pain, no conclusive evidence about causal mechanisms has been found. A number of authors (Merzenich et al., 1984; Calford and Tweedale, 1988; Garraghty and Kaas, 1991; Pons et al., 1991; Kaas, 1995) have reported massive reorganization of primary somatosensory cortex subsequent to amputation of individual digits or dorsal rhizotomy in monkeys and other species. It has been assumed (Katz, 1992b) that cortical reorganization might be an adaptive process after amputation that protects the amputee from the development of phantom limb pain. Contrary to this assumption, Flor et al. (1995) reported a high positive correlation $(r=0.93)$ between the magnitude of phantom limb pain and the amount of cortical reorganization.

The purpose of the present study was to determine the functional role of cortical reorganization for phantom limb pain.

\footnotetext{
Received Feb. 21, 1997; revised April 24, 1997; accepted April 28, 1997.

This work was supported by the Deutsche Forschungsgemeinschaft (research group "Clinical Psychophysiology" of Pain, Bi 195/24-6, and research group "Cortical Plasticity", F1 156/16-1). We appreciate the helpful comments of Thomas Elbert on this manuscript, the assistance of Hubert Preissl in the analysis of the MR and EEG data, the assistance of Oliver Schwarz in the anesthesia procedure, and the help of Karin Ritter and Alessandro Angrilli with data collection.

Correspondence should be addressed to Dr. Niels Birbaumer, Institute of Medical Psychology and Behavioral Neurobiology, University of Tübingen, Gartenstrasse 29, D-72074 Tübingen, Germany.

Copyright (C) 1997 Society for Neuroscience $\quad 0270-6474 / 97 / 175503-06 \$ 05.00 / 0$
}

Phantom limb pain was experimentally influenced by axillary brachial plexus anesthesia, and cortical reorganization was assessed as dependent variable. It was hypothesized that anesthesiainduced pain reduction should lead to a corresponding reduction in cortical reorganization. In cases in which anesthesia would not abolish phantom limb pain, cortical reorganization should remain unchanged.

\section{MATERIALS AND METHODS}

Subjects. Six unilateral arm amputees (mean age 56.0 years; SD $=22.6$ ) with phantom limb pain and four pain-free amputees (mean age 41.5 years; SD $=15.2$ ) were investigated. Demographic and clinical characteristics of the subjects are presented in Table 1. All subjects were male and had sustained traumatic amputations. Before the investigation they were informed about the possible consequences of the procedure, and they signed informed consent.

Stimulation. Light superficial pressure stimuli were applied to each of the following four sites: first and fifth digit of the intact hand and corner of the lower lip on both the intact and the amputation side. Each location was stimulated by a series of 1000 pneumatic stimuli (cf. Elbert et al., 1994; Yang et al., 1994; Flor et al., 1995) before and after a regional axillary brachial plexus anesthesia produced by infiltration of a local anesthetic agent. The four blocks of 1000 stimuli with a duration of 50 msec were delivered in random order to the four sites, with interstimulus intervals of $705 \mathrm{msec}$.

Assessment of pain and phantom phenomena. Pain was assessed by the German version of the West Haven-Yale Multidimensional Pain Inventory (MPI) that was adapted to measure both phantom limb and stump pain (Kerns et al., 1985; Flor et al., 1990) and a phantom limb and stump phenomena interview (Flor et al., 1995), which included the pain experience scale (Geissner et al., 1991) and a visual analog scale. All subjects participated in a neurological and psychophysical assessment, including detailed measurements of phantom phenomena, such as telescoping and "facial remapping" (Cronholm, 1951; Katz and Melzack, 1990; Ram- 
Table 1. Demographic and clinical characteristics of the amputees

\begin{tabular}{|c|c|c|c|c|c|c|c|}
\hline Subject & $\begin{array}{l}\text { Age } \\
(\mathrm{yr})\end{array}$ & $\begin{array}{l}\text { Years since } \\
\text { amputation }\end{array}$ & $\begin{array}{l}\text { Phantom pain } \\
(\mathrm{MPI})^{a}\end{array}$ & $\begin{array}{l}\text { Phantom sensation } \\
(0-3)\end{array}$ & $\begin{array}{l}\text { Stump pain } \\
(0-3)\end{array}$ & $\begin{array}{l}\text { Stump sensation } \\
(0-3)\end{array}$ & $\begin{array}{l}\text { Cortical } \\
\text { reorganization } \\
\text { (degrees) }\end{array}$ \\
\hline \multicolumn{8}{|c|}{ Phantom pain subjects } \\
\hline $\operatorname{Pr} 1^{b}$ & 61 & 20 & 3.33 & 0.00 & 1.32 & 0.00 & 6.8 \\
\hline $\operatorname{Pr} 2$ & 29 & 8 & 3.67 & 0.62 & 0.00 & 0.00 & 8.4 \\
\hline Pr3 & 56 & 28 & 4.30 & 1.00 & 0.00 & 0.00 & 18.4 \\
\hline Npr1 & 37 & 11 & 3.00 & 1.15 & 0.00 & 0.00 & 6.1 \\
\hline Npr2 & 72 & 26 & 4.83 & 2.00 & 0.00 & 0.60 & 3.4 \\
\hline Npr3 & 40 & 15 & 4.00 & 0.30 & 0.00 & 0.00 & 16.3 \\
\hline \multicolumn{8}{|c|}{ Phantom pain-free subjects } \\
\hline Np1 & 57 & 6 & 0 & 0.00 & 0.00 & 0.00 & 0.1 \\
\hline $\mathrm{Np} 2$ & 51 & 37 & 0 & 0.23 & 0.00 & 0.00 & 1.3 \\
\hline $\mathrm{Np3}$ & 24 & 7 & 0 & 1.00 & 0.00 & 0.60 & 1.7 \\
\hline Np4 & 34 & 18 & 0 & 0.85 & 0.00 & 0.20 & 2.7 \\
\hline
\end{tabular}

${ }^{a}$ Pain severity scale of the West Haven-Yale multidimensional pain inventory; range 0-6.

${ }^{b} \operatorname{Pr} 1-3$, Subjects with pain reduction during anesthesia; npr1-3, subjects without pain reduction during anesthesia; np1-4; subjects without phantom limb pain.

achandran et al., 1992; Flor et al., 1995). During anesthesia, changes in phantom limb pain were assessed on an 11-point verbal rating scale ranging from $0=$ no pain to $10=$ unbearable pain. Pain assessments were made before anesthesia, 20 min after anesthesia, and subsequent to each set of 1000 stimuli.

Neuroelectric source imaging. Neuroelectric source imaging was used to determine the location of the center of cortical responsivity of the hand and the mouth. Somatosensory evoked potentials (SEPs) were obtained from 60 electrodes that were affixed to an elastic cap and spaced $3 \mathrm{~cm}$ apart (center to center) in a $6 \times 10$ rectangular array centered over the vortex $(\mathrm{Cz})$; a linked ear reference was used. EEG recordings took $\sim 90$ min. All signals were sampled at a rate of $1 \mathrm{kHz}$ with a bandpass from 0.1 to $200 \mathrm{~Hz}$ using a 64-channel Synamps amplifier. Trials that exceeded 200 $\mu \mathrm{V}$ in any channel were excluded from further analysis (median rejection rate: $11.2 \%$ ). Eye movement artifacts, determined from vertical and horizontal electro-oculographic recordings, were corrected using the algorithm incorporated in the Neuroscan software (Semlitsch et al., 1986). SEPs were filtered offline using a low-frequency cutoff $(8 \mathrm{~Hz})$ and transformed to a common average reference. For each somatosensory evoked field, a principal component analysis (PCA) was performed to achieve an improved signal-to-noise ratio. The PCA was computed for a time window ranging from $40 \mathrm{msec}$ before stimulus baseline through 85 msec after stimulus onset (125 data points), which was chosen on the basis of previous findings concerning the approximate time window for primary somatosensory cortex activity (Elbert et al., 1994, 1995; Flor et al., 1995). To increase the signal-to-noise ratio for the dipole fitting in the contralateral hemisphere, the overall weight of the SEPs from the hemisphere ipsilateral to the site of stimulation (which receives a lesser input from the stimulated side) was decreased. The amplitudes of the SEPs from the hemisphere ipsilateral to the site of stimulation were weighted in an exponential fashion with maximal input from the more medial electrodes and minimal input from the temporal locations. The amplitudes of the SEPs from the hemisphere contralateral to the site of stimulation were used in an unweighted fashion. The three-dimensional location of each dipole was then computed based on three-dimensional magnetic resonance (MR) coordinates (determined for each individual) of the 60 electrode positions, which had been marked individually with vitamin E capsules (Siemens Vision MR scanner: 198 slices, field of view $230 \mathrm{~mm}$, 3-D Flash; repetition time $=20 \mathrm{msec}$, echo time $=6 \mathrm{msec} ; \alpha=$ $30^{\circ}$ ). For each electrical field distribution, a spherical four-shell model of the head was fitted using a standard least squares fit algorithm of the electrode coordinates; the radii from the center to the scalp, skull, liquor, and cortex surface were estimated according to standard ratios (Cuffin and Cohen, 1979). A coordinate system was used that had its origin in the center of the sphere, its $z$ axis pointing toward $\mathrm{Cz}$, its $x$ axis oriented in the medial-lateral direction, and its $y$ axis pointed in the anteriorposterior direction (Fig. 1). A larger polar angle denotes a more lateral and inferior position of the respective location; a smaller polar angle is achieved by more medial and superior locations. Cortical reorganization was determined by computing the polar angle (referred to $\mathrm{Cz}$ ) of the

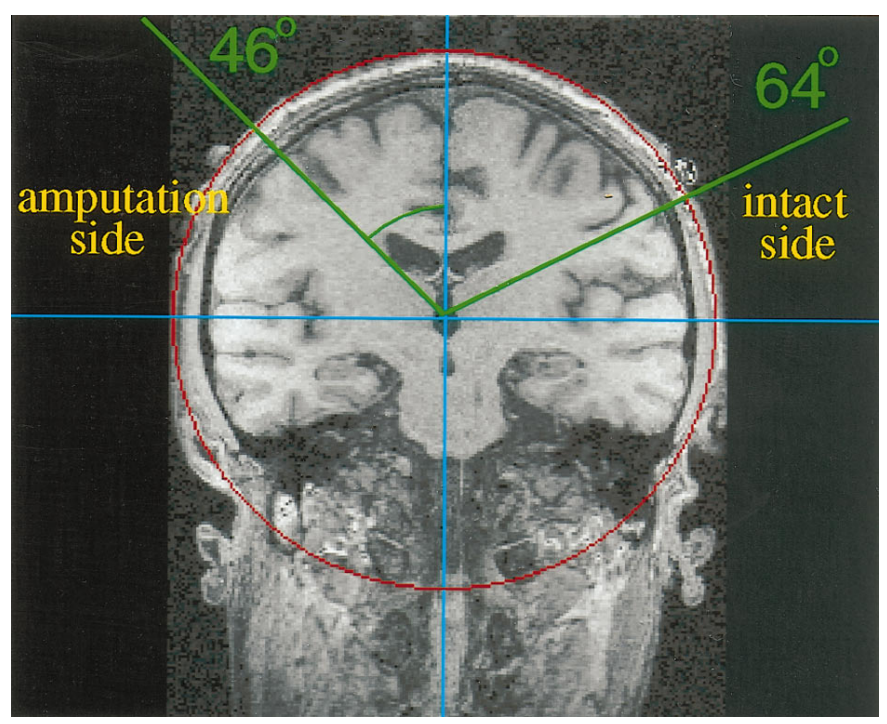

Figure 1. Coronal section through the postcentral gyrus (somatosensory cortex) of one phantom limb pain subject showing the pre-brachialplexus-blockade shift of the cortical lip representation into the amputation zone (smaller polar angle $46^{\circ}$, left side of figure) compared with the location of representation of the lip on the intact side (larger polar angle $64^{\circ}$, right side of figure). On the right side of the figure, the green line from the origin intersects the representation of the intact-side lip on the surface of the cortex; the line forms an angle of $64^{\circ}$ with the $z$ axis through $\mathrm{Cz}$. The green line on the left intersects the representation of the amputationside lip on the surface of the cortex; it makes a smaller angle with the $z$ axis through $\mathrm{Cz}\left(46^{\circ}\right)$, indicating that the representation of the lip on the amputation side had shifted into (invaded) the amputation zone, which had represented the now absent hand. Eighteen degrees $\left(64-46^{\circ}\right)$ represents $\sim 36 \mathrm{~mm}$ of cortical reorganization along the curved surface of the cortex (i.e., $\sim 2 \mathrm{~mm} /$ degree).

dipole locations of the finger and lip representations on the postcentral gyrus. For the correlations between cortical reorganization and pain, the MPI phantom limb pain values were rank-correlated with the difference in polar angle of the lip and finger representations of the intact minus the amputated side of the body. The polar angle of the (absent) finger on the amputation side was computed by projecting the finger representation of the intact side across the midline onto the hemisphere contralateral to the amputation stump, thus creating a "mirror" finger location of the amputation side (cf. Flor et al., 1995). 
Axillary brachial plexus blockade. Regional anesthesia has been used previously to investigate the central versus peripheral origin of pain (Lang et al., 1993). To produce regional anesthesia, $40 \mathrm{ml}$ of $1 \%$ mepivacaine (Niesel, 1994) combined with suprarenin $(1: 200,000$; to retard uptake of mepivacaine) (Singelyn et al., 1992) was infiltrated into the region of the brachial plexus by axillary injection. Assessment of the resorption of the anesthetic in the circulation (Bjork et al., 1990) was accomplished by taking blood samples $5,10,15,20,30,45,60$, and 120 min after the inception of the anesthesia. Tactile and pain thresholds were assessed by an anesthesiometer (Aglioti et al., 1994) subsequent to the beginning of anesthesia, both before and after the EEG assessment. Within 20 min after the injection, there was a complete anesthesia in the stump and the shoulder of all subjects that lasted until the end of the recording session. Analysis of blood samples (Adams et al., 1989) revealed an equal concentration of mepivacaine in all three groups of subjects (measurement after the last EEG recording: subjects with pain reduction, $2.06 \mu \mathrm{g} / \mathrm{ml}$; subjects without pain reduction, $2.89 \mu \mathrm{g} / \mathrm{ml}$; pain-free amputees, $2.12 \mu \mathrm{g} / \mathrm{ml}$ ).

\section{RESULTS}

\section{Cortical reorganization and phantom limb pain}

In the six phantom limb pain subjects, the cortical representation of the lip in the hemisphere contralateral to the amputation side was located, before brachial plexus blockade, significantly more medial and superior on the postcentral gyrus (mean polar angle $=$ $49.4^{\circ}$; $\mathrm{SD}=3.3$ ) than the cortical representation of the lip in the hemisphere contralateral to the intact side (mean polar angle $=$ $\left.59.4^{\circ} ; \mathrm{SD}=6.2 ; t_{(5)}=-4.02 ; p<0.01\right)$. This preblockade $9.9^{\circ}$ difference in polar angle (or $19.8 \mathrm{~mm}$ on the surface of the cortex), termed cortical reorganization, indicates that after amputation the representation of the amputation-side lip had shifted medially into the cortical region that had previously represented the now-amputated hand in persons experiencing phantom limb pain. In the phantom pain-free subjects, in contrast, the preblockade cortical representations of the lip in both hemispheres were symmetrical: mean polar angle $=52.6^{\circ}, \mathrm{SD}=6.3$ in the hemisphere ipsilateral to the amputation, and $51.2^{\circ}, \mathrm{SD}=6.5$ in the contralateral hemisphere; difference $=1.4^{\circ}(2.8 \mathrm{~mm})$; NS. This confirms our previous finding that there is a strong positive correlation between phantom limb pain and cortical reorganization. The correlation in this study was $0.78(p<0.01)$.

\section{Axillary brachial plexus blockade}

In three of the six amputees, phantom limb pain (verbal rating scale ranging from $0=$ no pain to $10=$ unbearable pain) was reduced from $4.2(\mathrm{SD}=3.3)$ to $0.4(\mathrm{SD}=0.5)$ within 20 min after regional anesthesia (pain reduction: $Z=-1.83$; $p<0.05$, onesided). In the remaining three subjects, phantom pain was unchanged [5.1 $(\mathrm{SD}=3.0)$ before anesthesia and 5.1 $(\mathrm{SD}=3.6)$ after anesthesia]. The phantom pain intensity results were mirrored almost exactly by the results for cortical reorganization. The three subjects who experienced phantom pain relief during anesthesia showed a very substantial mean reduction of cortical reorganization: $8.9^{\circ}\left(\mathrm{SD}=2.8 ; t_{(2)}=5.60 ; p<0.05\right)$ (Figs. 2,3$)$ or $17.8 \mathrm{~mm}$ on the surface of the cortex. That is, the cortical representation of the lip in the hemisphere contralateral to the amputation shifted laterally away from the amputation zone into which it had moved previously after amputation and assumed in general a slightly more frontal position (Fig. 3). In the three subjects without pain reduction and in the pain-free amputees, the cortical map remained unchanged after amputation stump anesthesia [mean shift of the lip representation: $0.8^{\circ}(\mathrm{SD}=10.0)$; NS] or $1.6 \mathrm{~mm}$.

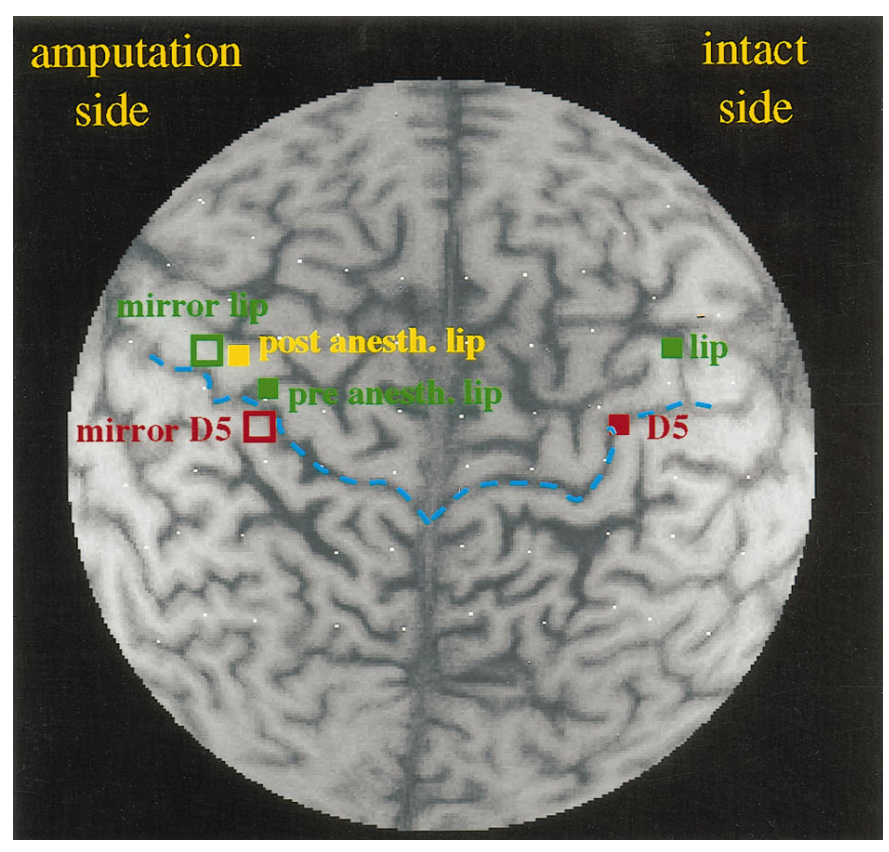

Figure 2. Cortical representation of the digits and the lower lip before and after brachial plexus blockade in a unilateral upper extremity amputee with phantom limb pain who experienced complete pain relief attributable to the regional anesthesia. The location of the representation of the fifth digit (D5) of the intact hand before anesthesia is indicated by the red filled square, and the locations of the representations of the lip of the intact side and of the amputated side by the green filled squares (pre anesth. lip). The mirror images of the intact digit and the intact lip projected onto the amputation-side hemisphere are marked by open squares of the same colors. These locations refer to the period before anesthesia. The location of the representation of the amputation-side lip after anesthesia (post anesth. lip) is indicated by the yellow filled square. The central sulci on both sides are marked in blue. Note that before brachial plexus blockade, the lip on the amputated side (green square) had shifted into the region occupied by the representation of the fingers on the intact side (mirror D5). Twenty minutes after amputation stump anesthesia, the phantom pain was almost eliminated; at the same time there was a dramatic shift of the amputationside lip back toward the position occupied by the lip representation on the intact side (mirror lip, open green square). The white dots are the vitamin E capsules marking the electrode positions.

\section{DISCUSSION}

\section{Functional relationship of phantom limb pain and cortical reorganization}

We have found previously that there is a very high positive correlation between phantom limb pain and plastic changes in primary somatosensory cortex of upper extremity amputees (Flor et al., 1995). There was, however, nothing in the data to establish a functional relationship between the two. The cortical reorganization was clearly caused by the amputation, but it could have been an epiphenomenon that bore no functional relationship to the experience of phantom limb pain; however, the results from this study, which involves an experimental intervention, show that there is such a relationship. In three upper extremity amputees with substantial cortical reorganization and phantom limb pain, amputation stump anesthesia produced by brachial plexus blockade abolished all aspects of cortical reorganization that could be identified by neuroelectric source imaging and at the same time virtually eliminated the current experience of phantom limb pain. In marked contrast, in three other upper limb amputees with equivalent amounts of cortical reorganization and phantom limb pain, amputation stump anesthesia produced no appreciable re- 


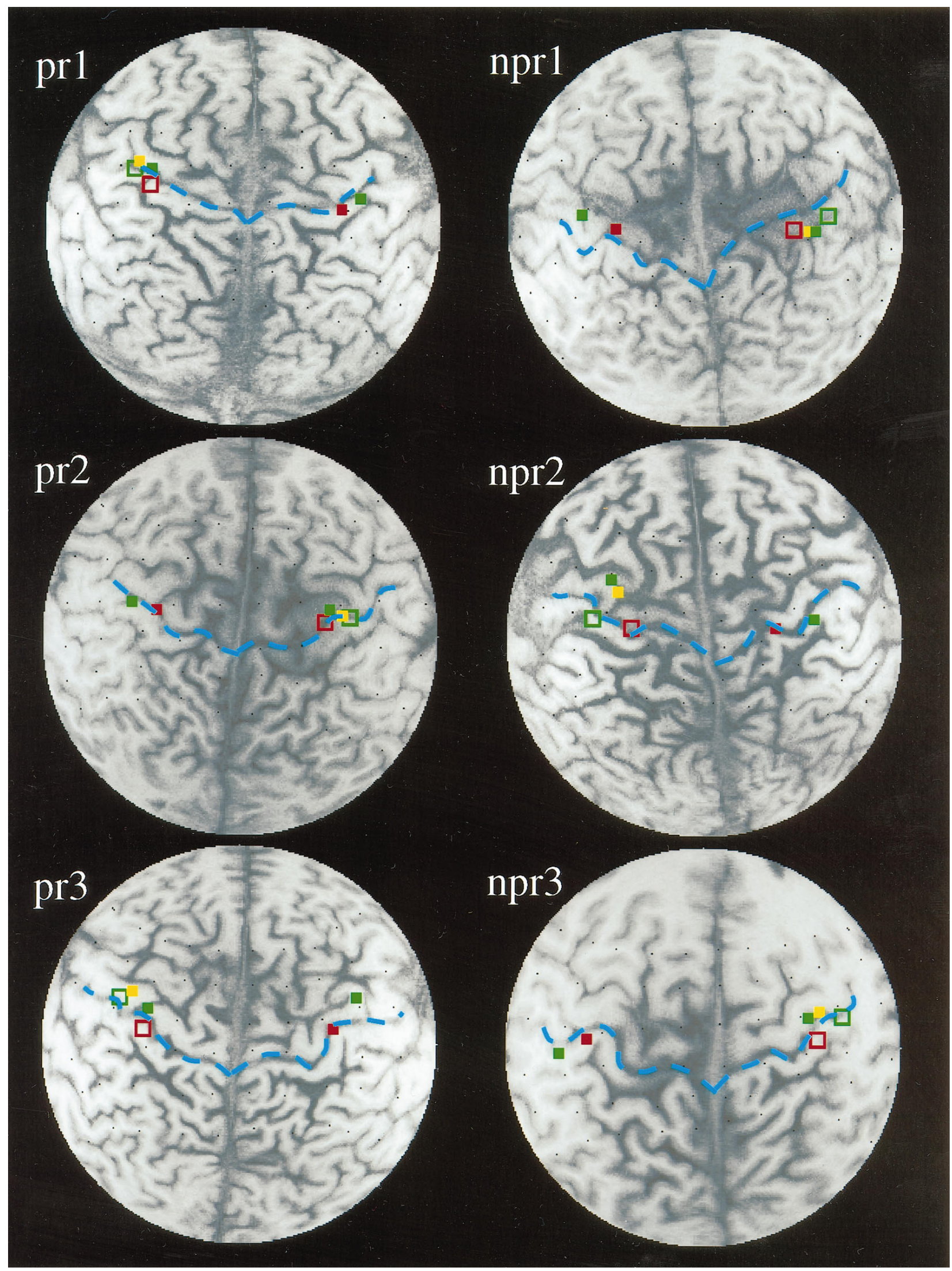

Figure 3. Cortical representation of the digits and the lower lip before and after brachial plexus blockade in the three amputees with reduction of phantom limb pain ( $p r 1, p r 2$, pr3; left) and the three amputees without phantom limb pain reduction (npr1, npr2, npr3; right). The central sulci on both sides are marked in blue. Note the shift of the lip representation back into a more lateral and frontal position in the upper limb amputees with phantom limb pain reduction attributable to anesthesia as compared with the relative lack of change in the amputees without pain reduction during anesthesia. 
duction in cortical reorganization and, similarly, no appreciable reduction in phantom limb pain.

These findings establish a functional link between cortical reorganization and phantom limb pain in upper extremity amputees; however, they do not define the causal nature of that relationship. The amputation stump anesthesia greatly reduced afferent input from that portion of the body. This could have eliminated the preexisting cortical reorganization, which in turn eliminated the phantom limb pain, or oppositely, the stump anesthesia could have eliminated the phantom limb pain, which had the effect of abolishing the cortical reorganization. Alternatively, the peripheral input from the stump may have been independently maintaining both cortical reorganization and phantom limb pain. Another possibility is that phantom limb pain and cortical reorganization after limb amputation are different manifestations of the same process; they are the same phenomenon that expresses itself with different characteristics in the different domains of the CNS and subjective experience. It is possible to experimentally distinguish between the first three possibilities, and it will be an important task for future research to do so, because the resolution of these issues has important implications for the discovery of an effective treatment for what can be a very severe pain syndrome that until now has been untreatable.

\section{Mechanisms of the relationship}

It is also important to note the remarkable speed with which amputation stump anesthesia abolished cortical reorganization in the subjects. This could be explained by a reversal of a previous unmasking process (Calford and Tweedale, 1991; Rossini et al., 1994) or by the suppression of deafferentation hyperexcitability (Rausell et al., 1992; Taub et al., 1995). In three of the present subjects, amputation stump anesthesia did not lead to either reduction in cortical reorganization or alleviation of phantom limb pain. The cortical alterations and the subjective phenomenon in these cases might be related to changes in intracortical synaptic connections that are more resistant to change based on either sprouting (Darian-Smith and Gilbert, 1994) or Hebbian synaptic changes leading to cell assembly formation (Birbaumer et al., 1990; Rauschecker, 1991; Diamond et al., 1994). The lack of efficacy of neurosurgical and pharmacological treatments targeting afferent mechanisms of phantom limb pain (Sherman et al., 1980) might be the result of these relatively enduring alterations (Flor and Birbaumer, 1994; Birbaumer et al., 1995). It is unlikely, however, that cortical reorganization maintains phantom limb pain by itself: removal of portions of the postcentral gyrus does not always successfully abolish phantom limb pain (for a review of the evidence on the role of cortex in pain, see Kenshalo and Douglass, 1995), and subcortical structures may also play an important role (cf. Florence and Kaas, 1995; Jain et al., 1997). The present findings establish that there is a functional relationship between cortical reorganization and phantom limb pain and suggest that phantom limb pain might be modulated by behavioral or pharmacological interventions that modify cortical reorganization.

\section{REFERENCES}

Adams HA, Biscoping J, Ludolf K, Borgmann A, Bachmann MB, Hempelmann G (1989) The quantitative analysis of amide local anesthetics using high pressure liquid chromatography and ultraviolet detection (HPLC/UV). Reg Anaesth 12:53-57.

Aglioti S, Bonazzi A, Cortese F (1994) Phantom lower limb as a perceptual marker of neural plasticity in the mature human brain. Proc $\mathrm{R}$ Soc Lond [Biol] 255:273-278.
Arena JG, Sherman RA, Bruno G, Smith JD (1990) The relationship between situational stress and phantom limb pain: cross-lagged correlational data from six month pain logs. J Psychosom Res 34:71-77.

Birbaumer N, Elbert T, Canavan A, Rockstroh B (1990) Slow potentials of the cerebral cortex and behavior. Physiol Rev 70:1-41.

Birbaumer N, Flor H, Lutzenberger W, Elbert T (1995) The corticalization of chronic pain. In: Pain and the brain: from nociception to cognition. (Bromm B, Desmedt JE, eds), pp 331-344. New York: Raven.

Bjork M, Pettersson KJ, Osterlof G (1990) Capillary gas chromatographic method for the simultaneous determination of local anaesthetics in plasma samples. J Chromatogr 533:229-234.

Calford MB, Tweedale R (1988) Immediate and chronic changes in responses of somatosensory cortex in adult flying-fox after digit amputation. Nature 332:446-448.

Calford MB, Tweedale R (1991) C-fibers provide a source of masking inhibition to primary somatosensory cortex. Proc R Soc [Biol] 243:269-275.

Cronholm B (1951) Phantom limbs in amputees. Acta Psychiatr Neurol Scand 72[Suppl]:1-310.

Cuffin BN, Cohen D (1979) Comparison of the magnetoencephalogram and electroencephalogram. Electroencephalogr Clin Neurophysiol 47:132-141.

Darian-Smith C, Gilbert CD (1994) Axonal sprouting accompanies functional reorganization in adult cat striate cortex. Nature 368:737-740.

Diamond M, Huang W, Ebner F (1994) Laminar comparison of somatosensory cortical plasticity. Science 265:1885-1888.

Elbert T, Flor H, Birbaumer N, Knecht S, Hampson S, Larbig W, Taub E (1994) Extensive reorganization of the somatosensory cortex in adult humans after nervous system injury. NeuroReport 5:2593-2597.

Elbert T, Junghöfer M, Scholz B, Schneider S (1995) The separation of overlapping neuromagnetic sources in first and second somatosensory cortices. Brain Topogr 7:275-282.

Flor H, Birbaumer N (1994) Acquisition of chronic pain: psychophysiological mechanisms. Am Pain Soc J 32:119-127.

Flor H, Rudy TE, Birbaumer N, Streit B, Schugens MM (1990) Zur Anwendbarkeit des West-Haven-Yale Multidimensional Pain Inventory im deutschen Sprachraum: Daten zur Reliabilität und Validität des MPI-D. Der Schmerz 4:82-87.

Flor H, Elbert T, Knecht S, Wienbruch C, Pantev C, Birbaumer N, Larbig W, Taub E (1995) Phantom-limb pain as a perceptual correlate of cortical reorganization following arm amputation. Nature 357:482-484.

Florence SL, Kaas JH (1995) Large-scale reorganization at multile levels of the somatosensory pathway follows therapeutic amputation of the hand in monkeys. J Neurosci 15:8083-8095.

Garraghty PE, Kaas JH (1991) Large-scale functional reorganization in adult monkey cortex after peripheral nerve injury. Proc Natl Acad Sci USA 88:6976-6980.

Geissner E, Dalbert C, Schulte A (1991) Möglichkeiten der Bestimmung affektiver und sensorischer Anteile der Schmerzempfindung. [Ways to determine affective and sensory components of the experience of pain]. Z Differt Diagn Psychol 12:145-162.

Jain N, Catania KC, Kaas JH (1997) Deactivation and reactivation of somatosensory cortex after dorsal spinal cord injury. Nature 386:495-498.

Jensen TS, Krebs B, Nielsen J, Rasmussen P (1985) Immediate and long-term phantom limb pain in amputees: incidence, clinical characteristics and relationship to pre-amputation limb pain. Pain 21:267-278.

Kaas JH (1995) The reorganization of sensory and motor maps in adult mammals. In: The cognitive neurosciences (Gazzaniga MS, ed), pp 51-71. Cambridge: MIT.

Katz J (1992a) Psychophysical correlates of phantom limb experience. J Neurol 55:811-821.

Katz J (1992b) Psychophysiological contributions to phantom limbs. Can J Psychiat 37:282-298.

Katz J, Melzack R (1990) Pain "memories" in phantom limbs: review and clinical observations. Pain 43:319-336.

Kenshalo DR, Douglass DK (1995) The role of the cerebral cortex in the experience of pain. In: Pain and the brain: from nociception to cognition (Bromm B, Desmedt J, eds), pp 21-34. Amsterdam: Elsevier.

Kerns RD, Turk DC, Rudy TE (1985) The West Haven-Yale Multidimensional Pain Inventory (WHYMPI). Pain 23:345-356.

Lang E, Erdmann K, Gerbershagen HU (1993) Median nerve blockade during diagnostic intravenous regional anesthesia as measured by somatosensory evoked potentials. Anesth Analg 6:118-122. 
Melzack R (1990) Phantom limbs and the concept of a neuromatrix. Trends Neurosci 13:88-92.

Melzack R (1995) Phantom limb pain and the brain. In: Pain and the brain: from nociception to cognition (Bromm B, Desmedt JE, eds), pp 73-82. New York: Raven.

Merzenich MM, Nelson RJ, Stryker MP, Cynader MS, Shoppmann A, Zook JM (1984) Somatosensory cortical map changes following digit amputation in adult monkeys. J Comp Neurol 224:591-605.

Niesel HC (1994) Klinische Pharmakologie und Toxikologie-Anwendung der Lokalanästhetika. In: Regionalanästhesie-LokalanästhesieRegionale Schmerztherapie (Niesel HC, ed), pp 69-149. Stuttgart: Thieme.

Pons TP, Garraghty PE, Ommaya AK, Kaas JH, Taub E, Mishkin MM (1991) Massive cortical reorganization after sensory deafferentation in adult macaques. Science 252:1857-1860.

Ramachandran VS, Stewart M, Rogers-Ramachandran DC (1992) Perceptual correlates of massive cortical reorganization. NeuroReport 3:583-586.

Rauschecker J (1991) Mechanisms of visual plasticity: Hebb synapses, NMDA receptors and beyond. Physiol Rev 71:587-615.

Rausell E, Cusick CG, Taub E, Jones EG (1992) Chronic deafferentation in monkeys differentially affects nociceptive and nonnociceptive pathways distinguished by specific calcium-binding proteins and downregulates $\gamma$-aminobutyric acid type A receptors at thalamic levels. Proc Natl Acad Sci USA 89:2571-2575.
Rossini PM, Martino G, Narici L, Pasquarelli A, Peresson M, Pizzella V, Tecchio F, Torrioli G, Romani GL (1994) Short-term brain "plasticity" in humans: transient finger representation changes in sensory cortex somatotopy following ischemic anesthesia. Brain Res 642:169-177.

Semlitsch HV, Anderer P, Schuster P, Presslich O (1986) A solution for reliable and valid reduction of ocular artifacts, applied to the P 300 ERP. Psychophysiology 23:695-703.

Sherman RA, Sherman CJ (1983) Prevalence and characteristics of chronic phantom limb pain among American veterans. Am J Phys Med 62:227-238.

Sherman RA, Sherman CJ, Gall NG (1980) A survey of current phantom limb pain treatment in the United States. Pain 8:85-99.

Sherman RA, Arena JG, Sherman CJ, Ernst JL (1989) The mystery of phantom pain: growing evidence for psychophysiological mechanisms. Biofeedback Self Regul 14:267-280.

Singelyn FJ, Dangoisse M, Bartholomee S, Gouverneur JM (1992) Adding clonidine to mepivacaine prolongs the duration of anesthesia and analgesia after axillary brachial plexus block. Reg Anaesth $17: 148-150$

Taub E, Flor H, Knecht S, Elbert T (1995) Correlation between phantom limb pain and cortical reorganization. J NIH Res 7:49-50.

Yang TT, Gallen, CC, Ramachandran VS, Cobb S, Schwartz BJ, Bloom FE (1994) Noninvasive detection of cerebral plasticity in adult human somatosensory cortex. NeuroReport 5:701-704. 